science available with a firm commitment to professionalism and a local management culture supportive of doctors, would be the best way of securing the rigour needed to command public trust and make revalidation feel fair and worth while for doctors.

With that secured, the profession would be in a strong position to join with the public and employers in a new partnership that could transform the outlook for patient centred health care in this country. And that could make for a much happier profession.

Contributors and sources: DI is a former family doctor and was president of the GMC when the 1990s reforms of medical regulation, including revalidation, were first introduced. This article reflects his open commitment to the principles of patient centred health care.

Competing interests: None declared.

1 Shipman Inquiry. Safeguarding patients: lessons from the past-proposals for the future. www.the-shipman-inquiry.org.uk/fifthreport.asp (accessed 19 Apr 2005)

2 Coulter A, Magee H, eds. The European patient of the future. Maidenhead: Open University Press, 2003.

3 Policy Commission on Public Services. Making public services personal: a new compact for public services. Report to National Consumer Council. London: NCC, 2004.

4 Schattner A, Rudin D, Jellin N. Good physicians from the perspective of their patients. BMC Health Services Research 2004;4:26.

Calnan MW, Sanford E. Public trust in healthcare: the system or the doctor? Qual Healthcare 2004;13:92-7.
6 Healthcare Commission. Patient survey report 2004-overview. London: Healthcare Commission, 2004

7 Department of Health. Supporting doctors: protecting patients. London: $\mathrm{DoH}, 1999$.

8 Irvine DH. The doctors' tale: professionalism and public trust. Oxford: Radcliffe Medical Press, 2003

9 Irvine DH. 17th Gordon Arthur Ransome oration: patient-centred professionalism. Ann Acad Med Singapore 2004;33:2-6.

10 Coulter A. The autonomous patient. London: Stationery Office, 2002

11 Anderson RM, Funnell MM, Butler PM, Arnold MS, Fitzgerald JT, Feste CC. Patient empowerment-results of a randomised trial. Diabetes Care 1995;18:943-9.

12 Bauman AE, Fardy JH, Harris PG. Getting it right: why bother with patient-centred care? Med J Aust 2003;179:253-6.

13 House of Lords Select Committee on the Constitution. The regulatory state: ensuring its accountability. Sixth report of session 2003-04. London: Stationery Office, 2004

14 General Medical Council. Good medical practice. London: GMC, 2004.

15 Bristol Royal Infirmary Inquiry. Learning from Bristol:the report of the public inquiry into children's heart surgery at the Bristol Royal Infirmary 1984-1995. London: Stationery Office, 2001.

16 NHS heart surgery data. Guardian 2005 Mar 16.

17 Keogh B, Kinsman R. Fifth national adult cardiac surgical database report. London: Society of Cardiothoracic Surgeons of Great Britain and Ireland, Dendrite Clinical Systems, 2003.

18 Bridgewater B. Mortality data in adult cardiac surgery for named surgeons: retrospective examination of prospectively collected data on coronary artery surgery and aortic valve replacement. BMJ 2005; 330:506-10.

19 General Medical Council. Revalidating doctors: ensuring standards, securing the future. London: GMC, 2000.

20 Pereira Gray D, Price A, Pringle M, Davis P, Baker M, Bailey J. Fellowship by assessment. 2nd ed London: Royal College of General Practitioners, 1995. Faser RC, Baker R. Model for directly assessing and improving clinical competence and performance in revalidation of clinicians. BMJ 2001;322:712-5.

\section{Ulysses syndrome}

What are the two hardest things to do in medicine? To say nothing (or "I don't know") and to do nothing. We have all felt parents' disappointment at the end of a consultation. So, rather than discharge their child, we offer a follow-up appointment, hoping that by then the parents will be more accepting of the situation or that they will be seen by a different doctor. However well meaning our action may be, it medicalises the child's condition: the parents may well feel that their child must have a serious problem because he or she is "under" a specialist.

We might also request another test, and risk inducing "Ulysses syndrome." Ulysses fought in the Trojan war but afterwards took 10 years, with many dangerous and often pointless adventures, before he got back to where he had started. Patients with Ulysses syndrome find themselves caught in a web of further investigations, referrals, and sometimes treatment before finally being recognised as healthy, which they were in the first place. Ulysses syndrome is a side effect of unnecessary and inappropriate investigations or wrong interpretation of results. It was first described 30 years ago, ${ }^{1}$ and the number of tests available is now much greater. With greater choice comes greater responsibility and the need for greater discernment. Otherwise we may condemn our patients to a similar odyssey.

When a colleague (A W Coe) and I reviewed the records of children on the waiting list for magnetic resonance imaging of the brain we found that half had not had their head circumference measured, a basic indicator of brain growth. Yet $£ 400$ brain scans had been requested, few of which would alter the clinical management and some of which would lead to further referrals and investigations because of results that would turn out to be normal variations.
The upper and lower $2.5 \%$ of the normal distribution of results are usually deemed to be abnormal, so $5 \%$ of the population are labelled "abnormal" even though they are probably healthy. If you request an unnecessary test in order to please the child's parents and to satisfy your wish to do something, what do you do if the results are slightly outside the normal range? Do you reassure the parents that it is probably a normal variation, or do you suggest repeating the test "to be on the safe side"? Do you admit the child for further investigation? At the very least you have set in train a very anxious time for the parents, further tests on the child, and at least one further outpatient appointment. The worried parents may even arrange for a second opinion, leading to more appointments and investigations on the child. Such needless procedures are a side effect of an unnecessary investigation and uncritical practice.

Charles Essex consultant neurodevelopmental paediatrician, Child Development Unit, Gulson Hospital, Coventry(room101@nttworld.com)

1 Rang M. The Ulysses syndrome. Can Med Assoc J 1972;106: 122-3.

We welcome articles up to 600 words on topics such as A memorable patient, A paper that changed my practice, My most unfortunate mistake, or any other piece conveying instruction, pathos, or humour. Please submit the article on http://submit.bmj.com Permission is needed from the patient or a relative if an identifiable patient is referred to. We also welcome contributions for "Endpieces," consisting of quotations of up to 80 words (but most are considerably shorter) from any source, ancient or modern, which have appealed to the reader. 